\title{
Advances in GLP-1 treatment: focus on oral semaglutide
}

\author{
Freddy G. Eliaschewitz ${ }^{1 *}$ and Luis Henrique Canani ${ }^{2}$
}

\begin{abstract}
Background: There is currently a large arsenal of antidiabetic drugs available to treat type 2 diabetes (T2D). However, this is a serious chronic disease that affects millions of adults worldwide and is responsible for severe complications, comorbidities, and low quality of life when uncontrolled due mainly to delays in initiating treatment or inadequate therapy. This review article aims to clarify the therapeutic role of the oral formulation of the glucagon-like peptide 1 receptor agonist (GLP-1 RA) semaglutide in treating typical T2D patients. The discussion focused on metabolic, glycemic, and weight alteration effects and the safety of the therapy with this drug.

Main text: Therapy with glucagon-like peptide 1 receptor agonist (GLP-1 RA) promotes strategic changes in the pathophysiological pathway of T2D and improves the secretion of glucagon and insulin, which results in a reduction in blood glucose levels and the promotion of weight loss. Until recently, the only route for semaglutide administration was parenteral. However, an oral formulation of GLP-1 RA was recently developed and approved by the Brazilian Health Regulatory Agency (ANVISA) and the Food and Drug Administration (FDA) based on the Peptide Innovation for Early Diabetes Treatment (PIONEER) program results. A sequence of 10 clinical studies compared oral semaglutide with placebo or active standard-of-care medications (empagliflozin $25 \mathrm{mg}$, sitagliptin $100 \mathrm{mg}$, or liraglutide $1.8 \mathrm{mg}$ ) in different T2D populations.

Conclusions: Oral semaglutide effectively reduces glycated hemoglobin ( $\mathrm{HbA1c}$ ) levels and body weight in a broad spectrum of patients with T2D and shows cardiovascular safety. Oral semaglutide broadens therapy options and facilitates the adoption of earlier GLP-1 RA treatment once T2D patients present low rates of treatment discontinuation. The main adverse events reported were related to the gastrointestinal tract, common to GLP-1 RA class drugs.
\end{abstract}

Keywords: Oral semaglutide, Glycemic control, GLP-1 RA, PIONEER program, Type 2 diabetes

\section{Background}

Diabetes mellitus is a major public health problem worldwide, as $10 \%$ of adults have the disease, which corresponded to 463 million individuals in the world in 2019 [1]. By 2045, this number will rise to 700 million [1]. Type 2 diabetes (T2D) corresponds to $90 \%$ of the cases, but $50.1 \%$ of these individuals did not have timely access to the diagnosis or appropriate treatment [1]. Moreover,

*Correspondence: freddy.g@uol.com.br

${ }^{1}$ CPClin/DASA Clinical Research Center, Avenida Angélica, 2162, São Paulo CEP 01228-200, Brazil

Full list of author information is available at the end of the article
374 million adults have insulin resistance, presenting a high risk for T2D [1]. The prevalence of T2D is rapidly increasing in three regions of the world: South America, Asia, and Eastern Europe [1]. Brazil is one of the 10 countries with the highest number of patients with diabetes mellitus [2], with a prevalence of $11.9 \%$ [3], accounting for 12.5 million individuals in 2017 and 20.3 million by the year 2045 [2].

T2D is currently one of the top 10 causes of death worldwide; in addition to affecting the elderly, this disease continues to heavily affect patients under 60 years old and has an important economic impact: in 2019, the health costs of T2D reached $\$ 760$ billion in the world [1]. original author(s) and the source, provide a link to the Creative Commons licence, and indicate if changes were made. The images or other third party material in this article are included in the article's Creative Commons licence, unless indicated otherwise in a credit line to the material. If material is not included in the article's Creative Commons licence and your intended use is not permitted by statutory regulation or exceeds the permitted use, you will need to obtain permission directly from the copyright holder. To view a copy of this licence, visit http://creativecommons.org/licenses/by/4.0/. The Creative Commons Public Domain Dedication waiver (http://creativecommons.org/publicdomain/zero/1.0/) applies to the data made available in this article, unless otherwise stated in a credit line to the data. 
T2D is commonly associated with relevant clinical conditions that are implicated in worse prognosis, increased mortality, and negative impacts on patient health-related quality of life, such as obesity and cardiovascular disease (CVD) [4]. The prevalence of obesity in patients with T2D is three times higher than that observed in the general population [5]. In Brazil, 75\% of T2D patients are beyond the appropriate body mass index (BMI), and $30 \%$ have obesity [5]. Obesity increases the risk of death in patients with T2D, with an estimated $20 \%$ increase in mortality risk for each $5 \mathrm{~kg} / \mathrm{m}^{2}$ increase in BMI [6]. Furthermore, this association has a direct linear relationship, with the lowest mortality risk described among patients with BMI equal to $22.5-24.9 \mathrm{~kg} / \mathrm{m}^{2}$ [6]. Weight loss with diet and physical activity can prevent or reverse T2D [7]. The DIRECT trial demonstrates that a weight loss of approximately $15 \mathrm{~kg}$ can lead to T2D remission in approximately $80 \%$ of patients with obesity and T2D [8]. However, most drug classes involved in T2D therapy promote weight gain (insulin, sulfonylureas, and others) [9]. Therefore, it is important that antihyperglycemic therapies do not increase weight and ideally promote weight loss $[9,10]$.

CVD is considered the leading cause of death in patients with T2D [11]. The results from a global review that evaluated 57 worldwide articles showed that CVD was responsible for $50.3 \%$ (95\% CI 37.0-63.7\%) of all deaths in patients with T2D [11]. Globally, $32.2 \%$ of these patients had some form of CVD from 2007 to 2017 [11]. More recently, the CAPTURE study estimated that the prevalence of established CVD in nearly 10,000 adults with T2D across 13 countries was $34.8 \%$ (95\% CI 32.736.8\%) [12]. In Brazil, CAPTURE estimated that the CVD prevalence in T2D patients was $43.9 \%$ (95\% CI 40.946.8\%) [12]. More specifically, 37.6\% (95\% CI 34.7-40.5\%) had atherosclerotic CVD, 27.9\% (95\% CI 25.2-30.5\%) had coronary heart disease, $12.4 \%$ (95\% CI $10.4-14.4 \%$ ) had heart failure, $8.7 \%$ (95\% CI 6.8-10.5\%) had cerebrovascular disease, and 3.4\% (95\% CI 2.3-4.5\%) had carotid artery disease [12].

Controlling blood sugar is an extremely important practice to avoid or delay chronic diabetic complications [13]. According to the United Kingdom Prospective Diabetes Study (UKPDS), a decrease of $1 \%$ in glycated hemoglobin $(\mathrm{HbA} 1 \mathrm{c})$ results in a $21 \%$ reduction in the risk of any endpoint related to diabetes, $21 \%$ in the risk of death related to diabetes, $14 \%$ in the risk of myocardial infarction, and $37 \%$ in the risk of microvascular complications [13]. Notwithstanding the efforts to improve the treatment of T2D with the development of new drugs, the percentage of patients achieving optimal glycemic control (HbA1c < 7.0\%) is still lower than desired, and mortality remains high, indicating the necessity of new therapies for T2D [14]. The global perspective DISCOVER study program demonstrated that exists a failure to monitor blood glucose in T2D patients that results in poor levels of glycemic control at initiation of second line therapy, particularly in lower-middle- and upper-middleincome countries [15]. At this stage of treatment, 26.7\% of the tested patients had an HbA1c level $\geq 9.0 \%$ [15]. Lack of efficiency was the most stated reason for choosing a second-line therapy, followed by physician preference, patient request, and side effects [15]. T2D can be treated and managed by healthy eating, regular physical activity, and medications to lower blood glucose levels [16]. Insulin is also commonly used to control blood glucose in this cohort of individuals [16]. However, more recent treatments, including the glucagon-like peptide 1 receptor agonist (GLP-1 RA) class, are effective and have other protective benefits, such as CV safety, but are injectable [16].

This review article is about the therapeutic role of the oral formulation of the GLP-1 RA semaglutide in treating T2D based on the results obtained in the Peptide Innovation for Early Diabetes Treatment (PIONEER) program.

\section{The challenges of an oral peptide}

Peptides are short amino acid monomer chains that are smaller than 100 amino acids, placing them between small molecules and proteins [17]. The advantages of using a peptide as a potential therapeutic drug are numerous, with highlights including the broad range of targets, low toxicity, high chemical and biological diversity, high potency and selectivity, good efficacy, safety, tolerability, low accumulation in tissues, and standard synthetic protocols [18]. However, experts face several limitations during the development process of a peptide, including limited oral bioavailability, elevated production costs, short half-life, rapid clearance, low metabolic stability, poor membrane permeability, and a tendency for aggregation, and some peptides can have immunogenic sequences [18].

The development of multiple strategies allowed an increase in the absorption of administered peptide medications [19]. These approaches include (1) permeation enhancers that can target either the transcellular route or the paracellular route; (2) modulation of $\mathrm{pH}$; (3) direct enzyme inhibition; (4) peptide cyclization that removes exposed $\mathrm{N}$ and $\mathrm{C}$ termini from peptides and reduces the cleavage susceptibility by enzymes; (5) mucus-penetrating agents to enhance the rate of passage of peptides across the mucus barrier; (6) cell-penetrating peptides that interact with membrane glycosaminoglycans and deliver the peptide via exocytosis; (7) intestinal patches that physically protect a small reservoir of drug from local degradation while positioning the drug 
close to the absorptive epithelium; (8) hydrogels that facilitate prolonged retention and enable a prolonged peptide residency time within specific gut regions while simultaneously resisting enzymatic degradation; and (9) microneedle devices and milliposts that are important to minimize the effect of protein size on bioavailability [19].

Some preclinical trials successfully developed oral peptides; however, the clinical application did not show sufficient bioavailability, and the technology used needed to be improved $[19,20]$. Insulin provides an example of some clinical trials that evaluated the efficacy and safety of a rapid-acting oral insulin formulation as well as all the failures [21]. The trials tested distinct technical approaches, different targets (stomach, small intestine, or colon), and a wide range of drug delivery systems [21]. However, problems such as inter- or intraindividual variability, gastric emptying rate, food ingestion timing, and the risk of differences in pharmacodynamic responses potentially enhanced the likelihood of hypoglycemia [21].

\section{Development of oral semaglutide: a GLP-1 ra peptide}

GLP-1 is an intestinal hormone of the incretin family responsible for amplifying insulin secretion, suppressing glucagon release, delaying gastric emptying, and decreasing insulin resistance $[19,22]$. In the central nervous system, GLP-1 acts as a neurotransmitter responsible for signaling satiety via the brainstem-hypothalamus [23-25]. Peripherally, GLP-1 reduces energy intake and affects all components of appetite regulation: increased satiety and fullness and decreased hunger and prospective food consumption [26, 27]. Together, these effects promote physiological satiety $[28,29]$.

GLP-1 RA is an effective treatment option for T2D but was available only in parenteral formulations since peptide-based drugs, including GLP-1 RA, have very low bioavailability when administered orally [30,31]. Semaglutide is a GLP-1 RA that can be used subcutaneously once a week as a treatment for T2D [30,31]. This injectable molecule is a potent and long-acting GLP-1 analog with $94 \%$ homology with human native GLP-1 [32]. Three key structural differences provide the extended pharmacokinetics of this drug, namely, the substitution of Ala with Aib at position 8 that increases enzymatic (DPP4) stability, attachment of a linker and C18 di-acid chain at position 26 that provides strong binding to albumin and substitution of Lys with Arg at position 34 that prevents C18 fatty acid-binding at the wrong site [32]. The phase 3 clinical trial program (SUSTAIN) compared subcutaneous semaglutide to placebo or other active standardof-care medications in patients with T2D [30, 31]. These trials showed that the subcutaneous semaglutide group had a greater reduction in HbA1c and body weight loss rates and that the semaglutide had a well-characterized safety profile $[30,31]$. However, T2D requires long-term treatment, and in general, an oral formulation is preferred by patients and could improve medication adherence. [19]. The oral formulation of semaglutide was approved on September 20th, 2019, by the Food and Drug Administration (FDA) and on October 20th, 2020, by the Brazilian Health Regulatory Agency (ANVISA) to treat T2D based on the PIONEER program, a sequence of phase III clinical trials showing the efficacy and safety of oral semaglutide in comparison with placebo or other active standard-of-care medications [33, 34].

The coformulation of semaglutide with sodium $\mathrm{N}$-[8-(2-hydroxybenzoyl) amino] caprylate (SNAC), a transcellular permeation enhancer, ensured the bioavailability of the oral formulation [19]. In association with semaglutide, SNAC has a predominantly transcellular transit mode via the gastric epithelium, where absorption occurs 60-140 min after ingesting a tablet containing $10 \mathrm{mg}$ of semaglutide and $300 \mathrm{mg}$ of SNAC in humans and dogs [19]. SNAC probably also attenuates semaglutide enzymatic digestion as it increases the local gastric $\mathrm{pH}$ [19].

Phase I clinical trials showed that the concomitant use of contraceptive pills, omeprazole, or other drugs commonly prescribed for T2D, as well as renal failure (any degree), do not compromise oral semaglutide pharmacokinetics [35-37]. To ensure bioavailability, patients should take oral semaglutide in the morning in the fasting state with up to half a glass of water (approximately $120 \mathrm{~mL}$ ), at least $30 \mathrm{~min}$ before the ingestion of any food or other medications [19]. Patients should gradually increase the dose of oral semaglutide to minimize the risk of GI adverse events, starting with $3 \mathrm{mg}$ once daily and, after 30 days, increasing to $7 \mathrm{mg}$ and then, if necessary, to $14 \mathrm{mg}$ once daily [19].

\section{Design of the pioneer trials}

Based on a phase II clinical trial [38], a sequence of eight multicenter, randomized phase III clinical trials, the PIONEER program, assessed the efficacy and safety of oral semaglutide [39-46]. Together, the trials evaluated oral semaglutide in 6163 patients who were at least 18 years old, had a diagnosis of T2D for at least 90 days before screening, and, for most patients, had inadequate glycemic control [39-46]. These trials included patients at the beginning of treatment (PIONEER 1), patients with advanced disease (PIONEER 8), and special populations (PIONEER trials 5 and 6). Furthermore, the trials also evaluated oral semaglutide versus oral antidiabetic drugs (OADs) (PIONEER trials 2 and 3) or the GLP-1 RA liraglutide (PIONEER 4) and oral semaglutide in flexible doses (PIONEER 7) (Table 1) [39-46]. 
Table 1 Summary of design and primary endpoints across the PIONEER trials considering trial product without rescue medication (trial product estimand)

\begin{tabular}{|c|c|c|c|c|c|c|}
\hline Trial & Population $^{\mathrm{a}}$ & Primary endpoint & Treatment & $\begin{array}{l}\text { Results } \\
\text { primary } \\
\text { endpoint (\%) }\end{array}$ & EDT $(95 \% \mathrm{Cl})$ & $p$ \\
\hline \multirow[t]{4}{*}{ PIONEER 1} & \multirow{4}{*}{$\begin{array}{l}703 \text { adults with T2D uncontrolled } \\
\text { with diet and exercise }\end{array}$} & \multirow{4}{*}{$\begin{array}{l}\text { Change in } \mathrm{HbA} 1 \mathrm{c} \text { from baseline } \\
\text { to week } 26\end{array}$} & Sema 3 mg & -0.8 & $-0.7 \%(-0.9$ to -0.5$)$ & $<0.001$ \\
\hline & & & Sema $7 \mathrm{mg}$ & -1.3 & $-1.2 \%(-1.5$ to -1.0$)$ & $<0.001$ \\
\hline & & & Sema 14 mg & -1.5 & $-1.4 \%(-1.7$ to -1.2$)$ & $<0.001$ \\
\hline & & & Pbo & -0.1 & - & - \\
\hline \multirow[t]{2}{*}{ PIONEER 2} & \multirow{2}{*}{$\begin{array}{l}822 \text { adults with T2D uncontrolled } \\
\text { on metformin }\end{array}$} & \multirow{2}{*}{$\begin{array}{l}\text { Change in } \mathrm{HbA} 1 \mathrm{c} \text { from baseline } \\
\text { to week } 26\end{array}$} & Sema 14 mg & -1.4 & $-0.5 \%(-0.7$ to -0.4$)$ & $<0.0001$ \\
\hline & & & Empa 25 mg & -0.9 & - & - \\
\hline \multirow[t]{4}{*}{ PIONEER 3} & \multirow{4}{*}{$\begin{array}{l}1864 \text { adults with T2D uncon- } \\
\text { trolled with metformin and/or } \\
\text { sulfonylurea }\end{array}$} & \multirow{4}{*}{$\begin{array}{l}\text { Change in } \mathrm{HbA} 1 \mathrm{c} \text { from baseline } \\
\text { to week } 26\end{array}$} & Sema 3 mg & -0.5 & $0.2 \%(0.1-0.4)$ & $<0.001$ \\
\hline & & & Sema $7 \mathrm{mg}$ & -1.1 & $-0.3 \%(-0.4$ to -0.2$)$ & $<0.001$ \\
\hline & & & Sema 14 mg & -1.4 & $-0.6 \%(-0.7$ to -0.5$)$ & $<0.001$ \\
\hline & & & Sita $100 \mathrm{mg}$ & -0.8 & - & - \\
\hline \multirow[t]{4}{*}{ PIONEER 4} & \multirow{4}{*}{$\begin{array}{l}711 \text { adults with T2D on met- } \\
\text { formin with or without an } \\
\text { SGLT2 inhibitor }\end{array}$} & \multirow{4}{*}{$\begin{array}{l}\text { Change in } \mathrm{HbA} 1 \mathrm{c} \text { from baseline } \\
\text { to week } 26\end{array}$} & Sema 14 mg & -1.3 & $-0.2 \%(-0.3 \text { to }-0.1)^{b}$ & $0.0056^{b}$ \\
\hline & & & & & $-1.2 \%(-1.4 \text { to }-1.0)^{c}$ & $<0.001^{c}$ \\
\hline & & & Lira $1.8 \mathrm{mg}$ & -1.1 & - & - \\
\hline & & & $\mathrm{Pbo}$ & -0.1 & - & - \\
\hline \multirow[t]{2}{*}{ PIONEER 5} & \multirow{2}{*}{$\begin{array}{l}324 \text { adults with T2D and moder- } \\
\text { ate renal impairment on } \\
\text { metformin and/or sulfonylurea, } \\
\text { or basal insulin }\end{array}$} & \multirow{2}{*}{$\begin{array}{l}\text { Change in } \mathrm{HbA} 1 \mathrm{c} \text { from baseline } \\
\text { to week } 26\end{array}$} & Sema 14 mg & -1.1 & $1.0 \%(-1.2$ to -0.8$)$ & $<0.0001$ \\
\hline & & & $\mathrm{Pbo}$ & -0.1 & - & - \\
\hline \multirow[t]{2}{*}{ PIONEER 7} & \multirow{2}{*}{$\begin{array}{l}504 \text { adults with T2D inadequately } \\
\text { controlled on one of two oral } \\
\text { glucose-lowering drugs }\end{array}$} & \multirow{2}{*}{$\begin{array}{l}\text { Proportion of patients with } \\
\text { HbA1c less than } 7.0 \% \text { at week } \\
52\end{array}$} & Sema flex & 63 & - & $<0.0001$ \\
\hline & & & Sita $100 \mathrm{mg}$ & 28 & - & - \\
\hline \multirow[t]{4}{*}{ PIONEER 8} & \multirow{4}{*}{$\begin{array}{l}731 \text { adults with T2D under } \\
\text { insulin therapy with or without } \\
\text { metformin }\end{array}$} & \multirow{4}{*}{$\begin{array}{l}\text { Change in } \mathrm{HbA} 1 \mathrm{c} \text { from baseline } \\
\text { to week } 26\end{array}$} & Sema 3 mg & -0.6 & $-0.6(-0.7$ to -0.4$)$ & $<0.0001$ \\
\hline & & & Sema 7 mg & -1.0 & $-1.0(-1.2$ to -0.8$)$ & $<0.0001$ \\
\hline & & & Sema 14 mg & -1.4 & $-1.4(-1.6$ to -1.2$)$ & $<0.0001$ \\
\hline & & & $\mathrm{Pbo}$ & -0.0 & - & - \\
\hline
\end{tabular}

Cl confidence interval; Dula dulaglutide; EDT estimated treatment differences; Empa empagliflozin; Flex flexible dose (3, 7 or 14 mg); Lira liraglutide; Pbo placebo; Sema oral semaglutide; Sita sitagliptin; T2D type 2 diabetes

a Randomized

${ }^{\mathrm{b}}$ Versus liraglutide

cVersus placebo

In all PIONEER trials, typical T2D patients received gradually increased doses of oral semaglutide as described earlier, except for PIONEER 7, in which the medication dose started at $3 \mathrm{mg}$ and, after an 8-week interval, could be increased or decreased depending on the patient's glycemic response and gastrointestinal tolerability (flexible dose-adjustment approach) [39, 40, 42-46].

PIONEER trials 1,5 , and 8 evaluated the effects of oral semaglutide in comparison with placebo [39, 43, 46]. PIONEER 2 compared oral semaglutide with empagliflozin $25 \mathrm{mg}$, PIONEER trials 3 and 7 with sitagliptin $100 \mathrm{mg}$, and PIONEER 4 with placebo and liraglutide $1.8 \mathrm{mg}[40-42,45]$.

The PIONEER 5 trial evaluated patients with advanced disease (T2D mean duration of 14.0 years and taking metformin and/or sulfonylurea or insulin with or without metformin) [43]. Specifically, this trial intended to explore the efficacy and safety of oral semaglutide $14 \mathrm{mg}$ compared with placebo in individuals with T2D and moderate renal impairment [estimated glomerular filtration rate (eGFR), $30-59 \mathrm{~mL} / \mathrm{min} / 1.73 \mathrm{~m}^{2}$ ] [43]. Finally, the design of PIONEER 6 assessed cardiovascular (CV) outcomes of oral semaglutide treatment versus placebo in patients with $\mathrm{T} 2 \mathrm{D}$ at high $\mathrm{CV}$ risk [age $\geq 50$ years with established CV or chronic kidney disease (CKD), or age $\geq 60$ years with CV risk factors only] [44].

All PIONEER trials verified HbA1c and weight [3946]. PIONEER trials $1-5,7$, and 8 aimed to evaluate glycemic control as the primary endpoint and weight as the secondary endpoint [45]. On the other hand, the primary endpoint of PIONEER 6 was the time from randomization to the first occurrence of a major adverse CV event (MACE) [44]. The secondary endpoints included time from randomization to the first occurrence of an expanded composite $\mathrm{CV}$ endpoint; time from 
randomization to the first occurrence of the individual components of the expanded composite $\mathrm{CV}$ endpoint; time to the first occurrence of a composite of all-cause death, non-fatal myocardial infarction or non-fatal stroke; time to all-cause death; time to permanent trial drug discontinuation due to adverse events; the number of serious adverse events; and changes from baseline in a variety of laboratory and clinical assessments [44].

\section{Glycemic control in the pioneer program}

In PIONEER 1 , in patients with early T2D and management only by diet and exercise, once-daily oral semaglutide monotherapy at doses of 7 and $14 \mathrm{mg}$ significantly reduced HbA1c levels compared to placebo at week 26 [estimated treatment difference (ETD) $-1.2 \%, 95 \%$ confidence interval $(\mathrm{CI})-1.5$ to $-1.0(7 \mathrm{mg}) ;-1.4 \%$, 95\% CI -1.7 to -1.2 (14 mg); $\mathrm{p}<0.001$ for both] [39]. Furthermore, the use of oral semaglutide suggests improvement in pancreatic insulin secretion assessed through homeostasis model assessment of $\beta$-cell function (HOMA- $\beta$ ) [ETD 1.63\%, 95\% CI 1.44-1.85 (7 mg), 1.71\%, 95\% CI 1.51-1.93 (14 mg); $\mathrm{p}<0.001 \mathrm{for}$ both] [39]. The fasting C-peptide level represents the insulin that the pancreas itself produces and was also increased in the semaglutide group compared to the placebo group [ETD $1.11 \mathrm{ng} / \mathrm{ml}$, 95\% CI 1.02-1.20; $\mathrm{p}=0.01(7 \mathrm{mg}), 1.05 \mathrm{ng} / \mathrm{ml}, 95 \% \mathrm{CI}$ 0.97-1.14; $\mathrm{p}=0.19(14 \mathrm{mg})][39,47]$.

In PIONEER 4, the results were similar in that oral semaglutide $14 \mathrm{mg}$ treatment, in association with metformin with or without an SGLT2i, was superior to placebo in reducing $\mathrm{HbA} 1 \mathrm{c}$ at week 26 (ETD - 1.2\%, 95\% CI -1.4 to -1.0 ; $\mathrm{p}<0.001$ ) [42]. In this trial, oral semaglutide $14 \mathrm{mg}$ had significantly greater decreases in $\mathrm{HbA} 1 \mathrm{c}$ than both subcutaneous liraglutide (ETD - 0.2\%, 95\% CI -0.3 to $-0.1 ; \mathrm{p}=0.0056)$ and placebo (ETD $-1.2 \%$, $95 \% \mathrm{CI}-1.4$ to $-1.0 ; \mathrm{p}<0.0001$ ) at week 26 [42].

In PIONEER 2, oral semaglutide $14 \mathrm{mg}$ treatment resulted in superior changes in HbAlc from baseline at week 26 in patients with T2D uncontrolled with metformin compared with empagliflozin $25 \mathrm{mg}$ (ETD $-0.5 \%, 95 \% \mathrm{CI}-0.7$ to $-0.4 ; \mathrm{p}<0.0001$ ) [40]. In this trial, the HOMA- $\beta$ index was higher at week 26 in the oral semaglutide group than in the empagliflozin $25 \mathrm{mg}$ group (ETD 1.50\%, 95\% CI 1.39-1.62; p < 0.0001) [40]. The doses of 7 and $14 \mathrm{mg}$ of oral semaglutide administered to patients with T2D uncontrolled with metformin and/or sulfonylurea in PIONEER 3 were both superior to sitagliptin $100 \mathrm{mg}$ in decreasing HbA1c levels at week 26 [ETD $-0.3 \%, 95 \%$ CI -0.4 to $-0.2(7 \mathrm{mg}),-0.6 \%, 95 \%$ CI -0.7 to -0.5 (14 mg); $\mathrm{p}<0.001$ for both] [41].

In PIONEER 7, the proportion of patients achieving an HbA1c target of less than $7.0 \%(53 \mathrm{mmol} / \mathrm{mol})$ at week 52 was $63 \%$ using oral semaglutide with a flexible-dose adjustment strategy compared with $28 \%$ using sitagliptin $100 \mathrm{mg}$ ( $\mathrm{p}<0.0001)$ [45]. Oral semaglutide resulted in significantly greater decreases in HbA1c than sitagliptin $100 \mathrm{mg}$ did at week 52 (ETD, $-0.7 \%$; $95 \% \mathrm{CI}-0.9$ to $-0.5 ; \mathrm{p}<0.0001)$ [45].

PIONEER 5 included patients with moderate renal impairment taking metformin and/or sulfonylurea or insulin with or without metformin [43]. The study population was older than the other trials (70 years on average) [43]. In this population, $14 \mathrm{mg}$ of oral semaglutide was significantly more effective than placebo in reducing HbA1c levels at week 26 (ETD, $-1.0 \%$; 95\% CI -1.2 to $-0.8 ; \mathrm{p}<0.0001)$ [43].

In PIONEER 8, patients with advanced disease (T2D mean duration of 15.0 years and taking insulin with or without metformin) had significant reductions in $\mathrm{HbA1c}$ levels with both the $7 \mathrm{mg}$ dose and the $14 \mathrm{mg}$ dose compared with the placebo at week 26 [ETD - 1.0\%, 95\% $\mathrm{CI}-1.2$ to -0.8 (7 mg), $-1.4 \%, 95 \% \mathrm{CI}-1.6$ to -1.2 (14 mg); p < 0.0001 for both]. The observed effect was maintained until week 52 [ETD - 0.9\%, 95\% CI - 1.1 to $-0.6(7 \mathrm{mg}),-1.3 \%, 95 \% \mathrm{CI}-1.5$ to $-1.0(14 \mathrm{mg})$; $\mathrm{p}<0.0001$ for both] [46]. Additionally, at baseline, the overall mean total daily insulin dosage was 58 units [46]. During the 8-week study drug initiation period, a $20 \%$ reduction in this dosage was recommended when initiating oral semaglutide, with the majority $(75.3 \%)$ of patients having their insulin dosage reduced by $15-25 \%$, $8.4 \%$ with dose reduction $<15 \%$ and $3.4 \%$ with a $>25 \%$ reduction [46]. At week 26, patients using $7 \mathrm{mg}$ and $14 \mathrm{mg}$ of oral semaglutide reduced their insulin dosage when compared to placebo [ETD - 3 units, 95\% CI -6 to $-1 ; \mathrm{p}=0.0169(7 \mathrm{mg}),-6$ units, $95 \% \mathrm{CI}-8$ to $-3 ; \mathrm{p}<0.0001(14 \mathrm{mg})$ ] [46]. The observed effect was maintained until week 52 (ETD -8 units, $95 \% \mathrm{CI}-11$ to -4 (7 mg), -12 units, $95 \% \mathrm{CI}-15$ to -8 (14 mg); $\mathrm{p}<$ 0.0001 for both] [46].

Table 1 is a compilation of all the above data, and it considers the trial product as an estimand in evaluating the effect of oral semaglutide compared with placebo without the confounding effect of rescue medication. In other words, this estimand reflects the treatment effect for all randomized patients (trial product estimand).

\section{Weight loss in the pioneer program}

Independent of the T2D background of the patient, the PIONEER program showed that oral semaglutide treatment effectively reduced body weight compared with placebo or other active standard-of-care medications [39-43, 45, 46]. In PIONEER 4, patients with uncontrolled T2D taking metformin with or without an SGLT2i and treated with $14 \mathrm{mg}$ of oral semaglutide had a higher weight loss in the program compared with placebo 
at week 26 (ETD, $-4.0 \mathrm{~kg}$; 95\% CI -4.8 to -3.2 ; p < 0.0001 ), and this reduction was sustained at week 52 (ETD, $-3.8 \mathrm{~kg} ; 95 \% \mathrm{CI}-4.8$ to $-2.7 ; \mathrm{p}<0.0001$ ). In this trial, $14 \mathrm{mg}$ of oral semaglutide treatment also provided a pronounced body weight reduction compared to the GLP-1 RA liraglutide $1.8 \mathrm{mg}$ at week 26 (ETD, $-1.5 \mathrm{~kg} ; 95 \% \mathrm{CI}-2.2$ to $-0.9 ; \mathrm{p}<0.0001)$ and week 52 (ETD, $-1.8 \mathrm{~kg} ; 95 \% \mathrm{CI}-2.6$ to -1.0 ; $\mathrm{p}<0.0001$ ).

Compared with placebo, oral semaglutide was more effective in reducing body weight in PIONEER 1 at week 26 [ETD $-1.0 \mathrm{~kg}, 95 \% \mathrm{CI}-1.8$ to $-0.2 ; \mathrm{p}=0.01(7 \mathrm{mg})$, $-2.6 \mathrm{~kg}, 95 \% \mathrm{CI}-3.4$ to -1.8 ; $\mathrm{p}<0.001$ (14 mg)], PIONEER 5 even with patients taking metformin and/or sulfonylurea or insulin with or without metformin [ETD $-2.7 \mathrm{~kg}, 95 \% \mathrm{CI}-3.5$ to $-1.9 ; \mathrm{p}=0.0001(14 \mathrm{mg})$ ] and PIONEER 8 regardless of the background insulin at week 26 (ETD $-2.5 \mathrm{~kg}, 95 \% \mathrm{CI}-3.2$ to -1.8 (7 mg), $-3.7 \mathrm{~kg}, 95 \% \mathrm{CI}-4.4$ to -3.0 (14 mg); $\mathrm{p}<0.001$ for both] $[39,43,46]$. This efficacy in PIONEER 8 was longlasting and seen at week 52 [ETD $-3.5 \mathrm{~kg}, 95 \% \mathrm{CI}-4.5$ to $-2.6(7 \mathrm{mg}),-4.9 \mathrm{~kg}, 95 \% \mathrm{CI}-5.9$ to $-3.9(14 \mathrm{mg})$; $\mathrm{p}<0.0001$ for both] [46]. In this study, the authors highlighted that the significant reduction in weight concerning the placebo indicated that oral semaglutide might help overcome some side effects caused by insulin [46].

Compared with sitagliptin $100 \mathrm{mg}$, oral semaglutide was associated, in PIONEER 3, with significantly pronounced reductions in body weight with $7 \mathrm{mg}$ and $14 \mathrm{mg}$ doses at week 26 [ETD $-1.5 \mathrm{~kg}, 95 \%$ CI -2.0 to -1.1 (7 mg), $-2.6 \mathrm{~kg}, 95 \% \mathrm{CI}-3.1$ to -2.1 (14 mg); $\mathrm{p}<0.001$ for both] and week 52 [ETD $-1.5 \mathrm{~kg}, 95 \% \mathrm{CI}-2.1$ to $-0.9(7 \mathrm{mg}),-2.9 \mathrm{~kg}, 95 \% \mathrm{CI}-3.5$ to $-2.3(14 \mathrm{mg})$; $\mathrm{p}<0.001$ for both] [41]. After 52 weeks, a flexible dose of oral semaglutide also showed greater reductions in body weight in comparison with sitagliptin $100 \mathrm{mg}$ in PIONEER 7 (ETD $-2.2 \mathrm{~kg}, 95 \% \mathrm{CI}-2.9$ to -1.5 ; $\mathrm{p}<$ 0.0001 ) [45]. In patients receiving background metformin in PIONEER 2, oral semaglutide $14 \mathrm{mg}$ showed no inferiority against empagliflozin $25 \mathrm{mg}$ in reducing body weight at week 26 (ETD - $0.4 \mathrm{~kg}, 95 \% \mathrm{CI}-1.0$ to -0.1 ; $\mathrm{p}=0.1358$ ) [40]. However, $14 \mathrm{mg}$ of oral semaglutide achieved a significantly greater body weight reduction than $25 \mathrm{mg}$ of empagliflozin at week 52 (ETD $-0.9 \mathrm{~kg}$, $95 \% \mathrm{CI}-1.6$ to $-0.2 ; \mathrm{p}=0.0114$ ) [40]. In this trial, patients answered a questionnaire adapted from the Food Craving Record that showed that patients who received oral semaglutide reported greater food craving control and higher mood scores compared to empagliflozin $25 \mathrm{mg}$ [40]. This result might be associated with the fact that oral semaglutide at a dose of $14 \mathrm{mg}$ compared to placebo decreased energy intake in patients with T2D [48]. More specifically, ad libitum total daily energy intake was reduced by $5096 \mathrm{~kJ}$ (a relative difference of 38.9\%) in patients receiving oral semaglutide versus placebo in the lunch meal, evening meal, and evening snack boxes, resulting in dietary control and pronounced weight loss [48].

In summary, among patients spanning the continuum of T2D and with different background glucose-lowering medications, achieving a weight loss of at least $5 \%$ was greater with oral semaglutide $7 \mathrm{mg}(19-27 \%)$ and $14 \mathrm{mg}$ (30-44\%) versus placebo (3-15\%) and with oral semaglutide $14 \mathrm{mg}(30-44 \%)$ versus liraglutide $1.8 \mathrm{mg}(28 \%)$, empagliflozin $25 \mathrm{mg}$ (36\%), and sitagliptin $100 \mathrm{mg}(10 \%)$ [49].

Table 2 is a compilation of all data above and considering the trial product as an estimand.

\section{Oral semaglutide beyond glycemic control Efficacy and safety of oral semaglutide versus other GLP1-RA drugs}

A systematic literature review used a network metaanalysis tool to calculate the relative efficacy and safety of once-daily oral semaglutide $14 \mathrm{mg}$ versus dulaglutide $1.5 \mathrm{mg}$, twice-daily exenatide $10 \mu \mathrm{g}$, once-weekly exenatide $2 \mathrm{mg}$, once-daily liraglutide $1.8 \mathrm{mg}$, once-daily lixisenatide $20 \mu \mathrm{g}$, and once-weekly injectable semaglutide 0.5 and $1.0 \mathrm{mg}$ (all GLP-1 RA class drugs) using seven clinical trials [50]. The results showed that oral semaglutide significantly reduced $\mathrm{HbA} 1 \mathrm{c}$ levels if compared with dulaglutide $(-0.85 \%, 95 \% \mathrm{CI}-1.25$ to -0.45$)$, exenatide $[-0.93 \%, 95 \% \mathrm{CI}-1.32$ to -0.54 (dose $10 \mu \mathrm{g})$ and $-0.89 \%, 95 \% \mathrm{CI}-1.27$ to -0.51 (dose $2 \mathrm{mg}$ )], liraglutide $(-0.42 \%, 95 \% \mathrm{CI}-0.78$ to -0.05$)$, and lixisenatide $(-1.32 \%, 95 \%$ CI -1.74 to -0.91$)$ [50]. However, reductions in $\mathrm{HbA} 1 \mathrm{c}$ were similar for oral and injectable semaglutide [ $-0.32 \%, 95 \% \mathrm{CI}-0.72$ to 0.08 (dose $0.5 \mathrm{mg}$ ) and $0.08 \%, 95 \%$ CI -0.32 to 0.47 (dose $1.0 \mathrm{mg}$ )] [50]. Oral semaglutide also significantly reduced weight compared to exenatide $2 \mathrm{mg}(-2.21 \mathrm{~kg}, 95 \% \mathrm{CI}-3.45$ to -0.92$)$ and lixisenatide $(-2.39 \mathrm{~kg}, 95 \% \mathrm{CI}-3.66$ to -1.14$)$ [50]. The other comparators were similar to oral semaglutide in bodyweight reduction [50]. According to safety, oral semaglutide provided similar odds of experiencing nausea and diarrhea compared with all other GLP-1 RA comparators [50]. On the other hand, the chance of vomiting was lower for oral semaglutide compared with dulaglutide [Odds ratios (OR) $0.03,95 \%$ CI $0.01-0.73$ ] and lixisenatide (OR 0.06, 95\% CI 0.01-0.82) [50].

\section{Patient-reported outcomes}

Good outcomes related to T2D therapy are not only measured by evaluating HbA1C levels. The multidisciplinary team must understand their patients to optimize each patient's treatment experience. So, PIONEER 
Table 2 Summary of the body weight reduction across the PIONEER trials considering the trial product without rescue medication (trial product estimand)

\begin{tabular}{|c|c|c|c|c|c|c|c|}
\hline \multirow[t]{3}{*}{ Trial } & \multirow[t]{3}{*}{ Treatment } & \multicolumn{6}{|c|}{ Body weight (kg) } \\
\hline & & \multicolumn{3}{|c|}{ From baseline to week 26} & \multicolumn{3}{|c|}{ From baseline to week 52} \\
\hline & & $\begin{array}{l}\text { Mean } \\
\text { change } \\
(\mathrm{kg})\end{array}$ & EDT $(95 \% \mathrm{Cl}) \mathrm{kg}$ & $p$ & Mean change (kg) & EDT $(95 \% \mathrm{Cl}) \mathrm{kg}$ & $\mathrm{p}$ \\
\hline \multirow[t]{4}{*}{ PIONEER 1} & Sema 3 mg & -1.7 & $-0.2(-1.0$ to 0.6$)$ & 0.71 & - & - & - \\
\hline & Sema $7 \mathrm{mg}$ & -2.5 & $-1.0(-1.8$ to -0.2$)$ & 0.01 & - & - & - \\
\hline & Sema 14 mg & -4.1 & $-2.6(-3.4$ to -1.8$)$ & $<0.001$ & - & - & - \\
\hline & Pbo & -1.5 & - & - & - & - & - \\
\hline \multirow[t]{2}{*}{ PIONEER 2} & Sema 14 mg & -4.2 & $-0.4(-1.0$ to 1.0$)$ & 0.1358 & -4.7 & $-0.9(-1.6$ to -0.2$)$ & 0.0114 \\
\hline & Empa 25 mg & -3.8 & - & - & -3.8 & - & - \\
\hline \multirow[t]{4}{*}{ PIONEER 3} & Sema 3 mg & -1.3 & $-0.5(-1.0$ to -0.1$)$ & 0.03 & -1.7 & $-0.7(-1.3$ to -0.1$)$ & 0.02 \\
\hline & Sema 7 mg & -2.4 & $-1.5(-2.0$ to -1.1$)$ & $<0.001$ & -2.5 & $-1.5(-2.1$ to -0.9$)$ & $<0.001$ \\
\hline & Sema 14 mg & -3.6 & $-2.6(-3.1$ to -2.1$)$ & $<0.001$ & -4.2 & $-2.9(-3.5$ to -2.3$)$ & $<0.001$ \\
\hline & Sita $100 \mathrm{mg}$ & -0.7 & - & - & -0.9 & - & - \\
\hline \multirow[t]{4}{*}{ PIONEER 4} & Sema 14 mg & -4.7 & $-1.5(-2.2 \text { to }-0.9)^{\mathrm{a}}$ & $<0.0001^{\mathrm{a}}$ & -5.0 & $-1.8(-2.6 \text { to }-1.0)^{\mathrm{a}}$ & $<0.0001^{\mathrm{a}}$ \\
\hline & & & $-4.0(-4.8 \text { to }-3.2)^{b}$ & $<0.0001^{b}$ & & $-3.8(-4.8 \text { to }-2.7)^{b}$ & $<0.0001^{b}$ \\
\hline & Lira $1.8 \mathrm{mg}$ & -3.2 & - & - & -3.1 & - & - \\
\hline & $\mathrm{Pbo}$ & -0.7 & - & - & -1.2 & - & - \\
\hline \multirow[t]{2}{*}{ PIONEER 5} & Sema 14 mg & -3.7 & $-2.7(-3.5$ to -1.9$)$ & $<0.0001$ & - & - & - \\
\hline & $\mathrm{Pbo}$ & -1.1 & - & - & - & - & - \\
\hline \multirow[t]{2}{*}{ PIONEER 7} & Sema flex & - & - & - & -2.9 (SE 0.3) & $-2.2(-2.9$ to -1.5$)$ & $<0.0001$ \\
\hline & Sita $100 \mathrm{mg}$ & - & - & - & -0.8 (SE 0.3) & - & - \\
\hline \multirow[t]{4}{*}{ PIONEER 8} & Sema 3 mg & -1.3 & $-0.9(-1.6$ to -0.2$)$ & 0.0111 & -1.0 & $-1.6(-2.6$ to -0.7$)$ & 0.0009 \\
\hline & Sema 7 mg & -3.0 & $-2.5(-3.2$ to -1.8$)$ & $<0.0001$ & -2.9 & $-3.5(-4.5$ to -2.6$)$ & $<0.0001$ \\
\hline & Sema 14 mg & -4.1 & $-3.7(-4.4$ to -3.0$)$ & $<0.0001$ & -4.3 & $-4.9(-5.9$ to -3.9$)$ & $<0.0001$ \\
\hline & $\mathrm{Pbo}$ & -0.4 & - & - & 0.6 & - & - \\
\hline
\end{tabular}

Cl confidence interval; Dula dulaglutide; EDT estimated treatment differences; Empa empagliflozin; Flex flexible dose adjustment; Lira liraglutide; Pbo placebo; SE standard error; Sema oral semaglutide; Sita sitagliptin

${ }^{a}$ Versus liraglutide

${ }^{\mathrm{b}}$ Versus placebo

2, 4-8 measured patient-reported outcomes better understand the patient satisfaction with oral semaglutide and the impact of the treatment on well-being, quality of life, and weight-related quality of life compared with other active standard-of-care medications $[40,42,43,45,46]$. The results showed that oral semaglutide improved the feelings of unacceptably high blood sugars when compared with placebo or sitagliptin [42, 43, 45, 46]. Furthermore, when asked about craving control and craving for savory, patients also reported better feeling with oral semaglutide than empagliflozin [40]. The ETDs for general health and social functioning domains at week 26 significantly favored oral semaglutide over empagliflozin, whereas for role-physical and physical component summary domains at week 52 favored empagliflozin over oral semaglutide [40].

\section{Reduction of CV risk}

CVD is the primary cause of death in patients with T2D, and new glucose-lowering therapies must show $\mathrm{CV}$ safety [51]. In the SUSTAIN-6 trial, the subcutaneous injection of semaglutide once a week reduced the relative risk of MACE by $26 \%$ compared to placebo [52]. In this trial, GLP-1 RA showed CV benefits on blood pressure, vascular endothelium, atherosclerosis progression and inflammation, and myocardial ischemia [52]. Furthermore, a meta-analysis that compiled data from the SUSTAIN-6 trial showed that CV benefits were associated with decreases in HbA1c and body weight [51].

PIONEER 6 assessed the CV outcomes of $14 \mathrm{mg}$ of oral semaglutide in patients with T2D and high CV risk (defined as age $\geq 50$ years with established CVD or CKD or age $\geq 60$ years with CV risk factors only) [44]. This trial analyzed 3183 patients randomized to receive $14 \mathrm{mg}$ of oral semaglutide or placebo, both in addition to 
standard-of-care treatment [44]. The primary endpoint was the time from randomization to the first occurrence of a MACE, a composite of death from CV causes (including undetermined causes of death), nonfatal myocardial infarction, or nonfatal stroke [44]. The secondary $\mathrm{CV}$ endpoints included the time from randomization to the first occurrence of an expanded composite outcome consisting of the primary endpoint plus unstable angina or heart failure, both resulting in hospitalization; or a composite of death from any cause, nonfatal myocardial infarction, or nonfatal stroke; and the individual components of these composite outcomes [44]. Furthermore, reductions in HbA1c, body weight, and lipid levels were measured, and adverse events were reported [44].

PIONEER 6 had an average duration of 15.9 months [44]. In this period, $99.7 \%$ of the selected patients completed the study, $84.7 \%$ in the oral semaglutide arm, and $90.1 \%$ in the placebo arm [44]. Furthermore, $75 \%$ of them received oral semaglutide or placebo for more than 12 months, and GI adverse events were the main reason for discontinuation [44]. The baseline characteristics of the patients were similar in both groups [44]. At the beginning of the study, some patients used metformin, insulin, sulfonylureas, or iSGLT2, in addition to antihypertensive, hypolipidemic, and antiplatelet or antithrombotic agents [44]. Interventions to initiate or intensify antidiabetic therapy were more frequent in the placebo group [44].

PIONEER 6 showed noninferiority of $14 \mathrm{mg}$ of oral semaglutide compared to placebo related to $\mathrm{CV}$ events [44]. The primary outcome of a MACE occurred in 3.8\% versus $4.8 \%$ of patients treated with oral semaglutide or placebo, respectively [hazard ratio (HR) $0.79,95 \%$ CI $0.57-1.11 ; \mathrm{p}<0.001$ ] [44]. The outcomes from secondary endpoints showed that $0.9 \%$ versus $1.9 \%$ of patients died from CV causes (HR 0.49, 95\% CI 0.27-0.92); 2.3\% versus $1.9 \%$ had nonfatal myocardial infarction (HR 1.18, 95\% CI $0.73-1.90$ ); $0.8 \%$ versus $1.0 \%$ had nonfatal stroke (HR 0.74, 95\% CI $0.35-1.57$ ); and $1.4 \%$ versus $2.8 \%$ died from any cause (HR 0.51, 95\% CI 0.31-0.84), all treated with oral semaglutide or placebo, respectively [44]. No unexpected adverse events were reported [44]. The main adverse events were associated with the gastrointestinal tract (11.6\% oral semaglutide versus $6.5 \%$ placebo) and were responsible for discontinuing treatment in $6.8 \%$ of patients treated with oral semaglutide and $1.6 \%$ of those who received placebo [44]. Additionally, the levels of lowdensity lipoprotein cholesterol and triglycerides were modestly lower in the oral semaglutide group.

\section{Renal benefits of GLP-1 RA}

One of the main causes of CKD and end-stage renal disease is T2D [53]. In addition, diabetic kidney disease is a major cause of morbidity and mortality in diabetes [53]. Kidney problems directly impact the choice of glycemic control medication in patients with CKD [53]. For example, metformin might need dose adjustment if the eGFR is $<60 \mathrm{~mL} / \mathrm{min} / 1.73 \mathrm{~m}^{2}$ and is contraindicated if the eGFR is $<30 \mathrm{~mL} / \mathrm{min} / 1.73 \mathrm{~m}^{2}[53,54]$. On the other hand, patients with kidney impairment presenting an eGFR of $15 \mathrm{ml} / \mathrm{min} / 1.73 \mathrm{~m}^{2}$ theoretically can use some GLP-1 RAs, including subcutaneous semaglutide, once these drugs no longer need dose adjustment in these cases [53, 54].

A systematic review and meta-analysis compared kidney outcomes from seven trials with a total of 56,004 T2D participants treated with GLP-1 RA or placebo [55]. Lixisenatide (ELIXA trial), liraglutide (LEADER trial), subcutaneous semaglutide (SUSTAIN-6 trial), exenatide (EXSCEL trial), and dulaglutide (REWIND trial) were GLP-1 RA drugs evaluated for kidney outcomes in this meta-analysis [data for kidney events were not available for albiglutide (Harmony Outcomes) or oral semaglutide (PIONEER 6), so this analysis excluded the outcomes of these trials] [55]. Selected studies enrolled patients with recent acute coronary syndrome, stable cardiovascular disease, or cardiovascular risk factors [55]. After the period of the trial treatment, the main results showed that the worsening of glomerular filtration was similar in the GLP-1 RA group and the placebo group (HR 0.87, 95\% CI 0.73-1.03; $\mathrm{p}=0.098$ ), which indicated that these drugs did not affect kidney function [55]. Treatment with a GLP-1 receptor agonist reduced the broader composite kidney outcome [which consisted of the development of macroalbuminuria, worsening kidney function (doubling of serum creatinine or $40 \%$ or greater decline in eGFR), end-stage kidney disease, and kidney-related death] by $17 \%$ (HR 0.83 , 95\% CI 0.78-0.89), mainly due to a reduction in urinary albumin excretion [55].

The LEADER trial assessed a total of 9340 patients with T2D and high CV risk treated with semaglutide or placebo [56]. A secondary renal outcome of this trial was a composite of new-onset persistent macroalbuminuria, persistent doubling of the serum creatinine level, endstage renal disease, or death due to renal disease [56]. The results showed that renal outcomes were less frequent in the liraglutide group than in the placebo group (HR 0.78, 95\% CI, 0.67-0.92, p = 0.003) [56]. New-onset persistent macroalbuminuria occurred in fewer patients in the liraglutide group (HR 0.74, 95\% CI 0.60-0.91, p = 0.004) [56]. Furthermore, in patients with an elevated renal risk (microalbuminuria or macroalbuminuria), a renal outcome also occurred in fewer patients treated with liraglutide (HR 0.81, 95\% CI 0.68-0.96, $\mathrm{p}=0.02$ ) [56]. A real-life study that better represents the everyday clinical practice of T2D patients evaluated a total of 
38,731 individuals [57]. They were treated with a GLP-1 RA (liraglutide $92.5 \%$, exenatide $6.2 \%$, lixisenatide $0.7 \%$, and dulaglutide $0.6 \%$ ) or dipeptidyl peptidase 4 inhibitors [57]. Patients treated with GLP-1 RAs had a lower risk of serious renal events than those treated with dipeptidyl peptidase 4 inhibitors (HR 0.76, 95\% CI 0.68-0.85) [57]. Additionally, GLP-1 RAs were associated with a significantly lower risk of renal replacement therapy (HR 0.73, 95\% CI 0.62-0.87) and hospitalization for renal events (HR 0.73, 95\% CI 0.65-0.83) [57].

In PIONEER 5, all eligible patients had moderate renal impairment, and overall, renal function was unchanged during the trial period in both groups once the median eGFR ratios (week 31 follow-up relative to baseline) were similar in both groups [HR 1.02, 95\% CI 0.27-1.96 (oral semaglutide); HR 1.00, 95\% CI 0.68-2.17 (placebo)] [43]. Furthermore, two patients in the oral semaglutide group had three nonserious events, and one patient in the placebo group had a nonserious adjudication committeeconfirmed event of acute kidney injury and recovered [43].

Briefly, data about the effects of GLP-1 RAs on renal outcomes will be available [58]. The FLOW study is a randomized, double-blinded, parallel-group, placebocontrolled trial dedicated to clarifying the safety and impact of $1.0 \mathrm{mg}$ of semaglutide weekly in people with renal impairment and T2D on major adverse renal events [58]. The study was initiated in June 2019 and will be completed after a 3- to 5-year follow-up with 3508 participants recruited [58]. The primary endpoint of the FLOW study is a renal composite measure of a persistent eGFR decline $\geq 50 \%$ from the start of the trial, end-stage renal disease, death from renal disease, or death from CVD [58]. Secondary outcome measures include renal outcomes, cardiovascular outcomes, changes in body weight, glycemic control, and blood pressure [58].

\section{The safety of oral semaglutide}

The overall safety profile of oral semaglutide was similar in all PIONEER trials and was not unexpected, considering subcutaneous semaglutide and other GLP-1 RAs [39-46]. Adverse events related to oral semaglutide were mainly of mild or moderate severity and did not lead to permanent treatment interruption [39-46]. Premature discontinuation of the study drug due to adverse events was less than $15 \%$ in all studies and was more frequent in the oral semaglutide group than in the placebo or active standard-of-care group, mainly due to GI disorders (Table 3) [39-46]. The main adverse events reported in the PIONEER program were related to the GI tract, but of mild or moderate severity, and most were transient. Nausea (most common adverse event), vomiting, diarrhea, constipation, dyspepsia, and abdominal pain were the six most commonly reported events in the groups that received oral semaglutide compared to those who received placebo or comparators (Table 3) [39-46]. Adverse events were more common when the dose of oral semaglutide increased from 3 to $7 \mathrm{mg}$ or from 7 to $14 \mathrm{mg}$ [39-46].

The use of oral semaglutide did not significantly decrease the rate of patients who completed the treatment [39-46]. In the PIONEER program, the mean treatment adherence of patients who received oral semaglutide $14 \mathrm{mg}$, liraglutide $1.8 \mathrm{mg}$, empagliflozin $25 \mathrm{mg}$, sitagliptin $100 \mathrm{mg}$ and placebo were $82.6 \%$ (79.6-86.3\%), 83.7\%, 89.0\%, 88.9\% (86.9-90.8\%), and $88.8 \%(87.6-90.1 \%)$ respectively [39-46]. GI reactions were the main cause of withdrew the study in oral semaglutide group [39-46]. Oral semaglutide intake demands ingestion care, such as fasting state and caution for water intake, which may decrease patient adherence [19]. Future real-world data will be necessary to realize if this ingestion care will impact oral semaglutide adherence. However, the adherence rate of injectable semaglutide in SUSTAIN trial was very similar to oral semaglutide $(84.7 \%$ versus $82.6 \%$, respectively) [31, 39-46]. Furthermore, the adherence of injectable and oral placebo was also similar in SUSTAIN versus PIONEER studies $(89.7 \%$ versus $88.8 \%$, respectively) [31, 39-46].

Severe hypoglycemic episodes occurred more frequently in patients receiving basal insulin in association with oral semaglutide (PIONEER 8) (Table 3) [46]. In general, a symptomatic decrease in blood glucose was uncommon (less than $8 \%$ in all groups that received oral semaglutide). In addition, all cases of hypoglycemia were considered mild or moderate [39-46, 59, 60].

Worsening of renal function was not reported in any of the studies, including PIONEER 5, where T2D patients had established CKD [39-46]. Acute pancreatitis and acute kidney injury were rare and were similar among patients who received oral semaglutide and comparators [39-46]. Although other GLP1-RA treatment studies showed some increase in lipase and amylase production, this observation was not associated with clinical manifestations of acute pancreatitis [39-46, 61].

Patients treated with oral semaglutide or liraglutide had a small decrease in blood pressure and a slight increase in heart rate compared to patients treated with non-GLP-1 RA comparators [39-46]. Malignant neoplasms and death were rare adverse events and occurred with equal or less frequency in the oral semaglutide group than in the placebo group [39-46]. Few deaths occurred in the PIONEER program, and all of them were judged by the investigators as unlikely to be related to the study drug [39-46]. 
Table 3 Summary of safety data across the PIONEER trials

\begin{tabular}{|c|c|c|c|c|c|}
\hline \multirow[t]{2}{*}{ Trial } & \multirow[t]{2}{*}{ Treatment (n) } & \multicolumn{2}{|c|}{ Adverse events (n) } & \multirow{2}{*}{$\begin{array}{l}\text { Discontinuation due to } \\
\text { adverse events \% (n) }\end{array}$} & \multirow{2}{*}{$\begin{array}{l}\text { Severe } \\
\text { hypoglycemia } \\
\text { episodes }^{b} \% \text { (n) }\end{array}$} \\
\hline & & Total \% (n) & Serious $^{a} \%(n)$ & & \\
\hline \multirow[t]{4}{*}{ PIONEER 1} & Sema 3 mg (175) & $57.7(101)$ & $2.9(5)$ & $2.3(4)$ & 0 \\
\hline & Sema 7 mg (175) & $53.1(93)$ & $1.7(3)$ & $4.0(7)$ & $0.6(1)$ \\
\hline & Sema 14 mg (175) & $56.6(99)$ & $1.1(2)$ & $7.4(13)$ & 0 \\
\hline & Pbo (178) & $56.6(99)$ & $4.5(8)$ & $2.2(4)$ & 0 \\
\hline \multirow[t]{2}{*}{ PIONEER 2} & Sema 14 mg (410) & 70.5 (289) & $6.6(27)$ & $10.7(44)$ & $1.7(7)$ \\
\hline & Empa 25 mg (409) & $69.2(283)$ & $9.0(37)$ & $4.4(18)$ & $2.0(8)$ \\
\hline \multirow[t]{4}{*}{ PIONEER 3} & Sema 3 mg (466) & $79.4(370)$ & $13.7(64)$ & $5.6(26)$ & $4.9(23)$ \\
\hline & Sema 7 mg (464) & $78.2(363)$ & $10.1(47)$ & $5.8(27)$ & $5.2(24)$ \\
\hline & Sema 14 mg (465) & $79.6(370)$ & $9.5(44)$ & $11.6(54)$ & $7.7(36)$ \\
\hline & Sita 100 mg (466) & $83.3(388)$ & $12.4(58)$ & $5.2(24)$ & $8.4(39)$ \\
\hline \multirow[t]{3}{*}{ PIONEER 4} & Sema 14 mg (285) & $80.0(229)$ & $11.0(31)$ & $11.0(31)$ & $1.0(2)$ \\
\hline & Lira 1.8 mg (284) & $74.0(211)$ & $8.0(22)$ & $9.0(26)$ & $2.0(7)$ \\
\hline & Pbo (142) & $67.0(95)$ & $11.0(15)$ & $4.0(5)$ & $2.0(3)$ \\
\hline \multirow[t]{2}{*}{ PIONEER 5} & Sema 14 mg (163) & $75.0(122)$ & $12.0(20)$ & $15.0(24)$ & $6.0(9)$ \\
\hline & Pbo (161) & $68.0(109)$ & $11.0(18)$ & $5.0(8)$ & $2.0(3)$ \\
\hline \multirow[t]{2}{*}{ PIONEER 6} & Sema 14 mg (1591) & - & $18.9(301)$ & $11.6(184)$ & $1.4(23)$ \\
\hline & Pbo (1592) & - & $22.5(358)$ & $6.5(104)$ & $0.8(13)$ \\
\hline \multirow[t]{2}{*}{ PIONEER 7} & Sema Flex (253) & $78.0(197)$ & $9.0(24)$ & $9.0(22)$ & 0 \\
\hline & Sita 100 mg (250) & $69.0(172)$ & $10.0(24)$ & $3.0(8)$ & 0 \\
\hline \multirow[t]{4}{*}{ PIONEER 8} & Sema 3 mg (184) & $74.5(137)$ & $13.6(25)$ & $7.1(13)$ & $28.3(52)$ \\
\hline & Sema 7 mg (181) & $78.5(142)$ & $10.5(19)$ & $8.8(16)$ & $26.0(47)$ \\
\hline & Sema 14 mg (181) & $83.4(151)$ & $6.6(12)$ & $13.3(24)$ & $26.5(48)$ \\
\hline & Pbo (184) & 75.5 (139) & $9.2(17)$ & $2.7(5)$ & $29.3(54)$ \\
\hline
\end{tabular}

Dula dulaglutide; Empa empagliflozin; Flex flexible dose adjustment; Gl gastrointestinal; Lira liraglutide; $N$ number; Pbo placebo; Sema oral semaglutide; Sita sitagliptin

a Serious adverse events are based on patient/event outcome or action criteria usually associated with events that pose a threat to the patient's life or functioning

${ }^{\mathrm{b}}$ Hypoglycemic episodes were considered severe and defined as blood glucose lower than $56 \mathrm{mg} / \mathrm{dL}(<3.1 \mathrm{mmol} / \mathrm{L})$ associated with symptoms consistent with hypoglycemia (defined according to the American Diabetes Association classification)

\section{Benefits of early and effective treatment in T2D}

Approximately $80 \%$ of the annual cost of T2D to the United Kingdom National Health Service arises from dealing with potentially avoidable long-term complications of T2D [62]. A direct therapeutic intervention aimed at controlling the patient's glycemic costs at only $8 \%$ of the amount [62]. With this rationale, a study used the IMS Centre for Outcomes Research and Effectiveness (CORE) Diabetes Model (a nonproduct-specific diabetes policy analysis tool that performs real-time simulations developed by IMS Health, Danbury, CT, USA) to examine the impact of improved glycemic control in patients with T2D [62]. The results clearly show that modest improvements in glycemic control in T2D and sustained $\mathrm{HbA1c}$ control can significantly reduce the rates of diabetes-related microvascular complications and reduce foot ulcers, amputations, and neuropathy, which can reduce the current cost of T2D by 57\% [62]. Besides decreasing the future treatments with comorbidities related to T2D, the adequate use of oral semaglutide $14 \mathrm{mg}$ was considered a cost-effective treatment option versus empagliflozin $25 \mathrm{mg}$, sitagliptin $100 \mathrm{mg}$, and liraglutide $1.8 \mathrm{mg}$ in the United Kingdom and the Netherlands [63, 64]. Based on long-term projections, diabetes-related complications were fewer with oral semaglutide of $14 \mathrm{mg}$, which yielded cost savings that partially offset its higher treatment costs versus empagliflozin and sitagliptin [63, 64]. Related to liraglutide, the treatment itself, even without considering costs with comorbidities, was lower with oral semaglutide $[63,64]$.

The importance of early and effective treatment was also discussed by Defronzo when he proposed that the T2D treatment algorithm must change [65]. Instead of a treatment that focuses on glucose control, the proposal goal was a therapy that should delay disease progression and eventual treatment failure based on the pathophysiology of T2D [65, 66]. The pathophysiologic abnormalities involved in glucose intolerance in T2D include (1) $\beta$-cell failure; (2) insulin resistance in muscle; (3) insulin resistance in the liver; (4) insulin resistance in adipocytes 
(increased lipolysis); (5) reduced incretin secretion and sensitivity (gastrointestinal); (6) increased glucagon secretion ( $\alpha$-cells); (7) enhanced glucose reabsorption (kidney); and (8) central nervous system insulin resistance resulting from neurotransmitter dysfunction (brain) $[65,66]$. Together, these eight pathogenic mechanisms complete the T2D "ominous octet" $[65,66]$. According to Defronzo, optimal management of T2D should include early initiation of therapy using multiple drugs, with different mechanisms of action, in combination [65]. However, oral semaglutide and other GLP-1 RA drugs act by increasing insulin secretion, inhibiting glucagon secretion that leads to reduced hepatic glucose production, correcting defects in the production of gastrointestinal incretins, and promoting an effect on the central nervous system that leads to appetite suppression and weight loss, which is reflected in increased muscle and liver sensitivity to insulin $[67,68]$. That is, oral semaglutide corrects seven of the eight mechanisms involved in the pathophysiology of T2D [67].

\section{Conclusions}

The innovative development of an oral formulation for the GLP-1 RA semaglutide was a major therapeutic advance for T2D. Phase II clinical trials and the PIONEER program thoroughly evaluated and proved the bioavailability, efficacy, and safety of oral semaglutide across the T2D spectrum. Different backgrounds of patients can use oral semaglutide, especially those who do not want to use injectable medication. More specifically, the PIONEER program showed that oral semaglutide is efficacy and safe for adults with early T2D managed by diet and exercise, adults with advanced disease requiring daily insulin, and adults with CVD and/or CKD. Furthermore, this drug was more effective than comparators for glycemic control and weight loss. The expectation is that the oral formulation will increase patient adherence to treatment, which is essential in controlling blood glucose and reducing complications and comorbidities. Comparisons between oral semaglutide and other medications not included in the PIONEER program, such as injectable semaglutide, could be considered a limitation of this study because they had different methodologies, dosages, and treatment times. In the future, Real-world data will be required to confirm if the outcomes seen in the PIONEER program are translated into clinical practice.

\footnotetext{
Abbreviations

ADA: American Diabetes Association; ANVISA: Brazilian Health Regulatory Agency; BMI: Body mass index; Cl: Confidence interval; CKD: Chronic kidney disease; CV: Cardiovascular; CVD: Cardiovascular disease; EASD: European Association for the Study of Diabetes; eGFR: Estimated glomerular filtration rate; ETD: Estimated treatment difference; FDA: Food and Drug Administration; Gl: Gastrointestinal; GLP-1 RA: Glucagon-like peptide 1 receptor agonist;
}

HbA1c: Glycated hemoglobin; HOMA- $\beta$ : Homeostasis model assessment of $\beta$-cell function; HR: Hazard ratio; kg: Kilograms; kJ: Kilojoules; m: Meter; MACE: Major adverse cardiovascular event; mg: Milligrams; OR: Odds ratios; PIONEER: Peptide Innovation for Early Diabetes Treatment; SGLT2i: Sodium-glucose cotransporter 2 inhibitor; SNAC: Sodium N-[8-(2-hydroxybenzoyl) amino] caprylate; T2D: Type 2 diabetes; TZD: Thiazolidinedione; UKPDS: United Kingdom Prospective Diabetes Study.

\section{Acknowledgements}

The authors would like to thank Monique Thaís Costa Fonseca for writing assistance on behalf of Springer Healthcare.

\section{Authors' contributions}

The authors designed, reviewed, and approved the manuscript. All authors read and approved the final manuscript.

\section{Funding}

Financial support for this work was provided by Novo Nordisk Farmacêutica do Brasil LTDA.

Availability of data and materials

Not applicable.

\section{Declarations}

Ethics approval and consent to participate

Not applicable.

\section{Consent for publication}

If the manuscript is accepted, I agree to its publication in Diabetology and Metabolic Syndrome.

\section{Competing interests}

FGE: Advisory board for AstraZeneca, Novonordisk, Sanofi. Lectures: Bayer, Lilly, AstraZeneca, Novo Nordisk, Sanofi, Abbott, Merck, Novartis. LHC: Speaker for Novo Nordisk. Researcher in the PIONEER Program.

\section{Author details}

${ }^{1}$ CPClin/DASA Clinical Research Center, Avenida Angélica, 2162, São Paulo CEP 01228-200, Brazil. ${ }^{2}$ Endocrinology Division of Hospital de Clínicas de Porto Alegre and Department of Internal Medicine, Medical School of Federal, University of Rio Grande Do Sul, Porto Alegre, Brazil.

Received: 18 June 2021 Accepted: 23 August 2021

Published online: 15 September 2021

\section{References}

1. International Diabetes Federation. IDF Diabetes Atlas. 2019. 9th edition https://www.diabetesatlas.org/en/. Accessed 15 Jan 2021.

2. International Diabetes Federation. IDF Diabetes Atlas. 2017. 8th edition. https://www.diabetesatlas.org/upload/resources/previous/files/8/IDF_ DA_8e-EN-final.pdf. Accessed 17 Feb 2021.

3. Telo $\mathrm{GH}$, et al. Prevalence of diabetes in Brazil over time: a systematic review with meta-analysis. Diabetol Metab Syndr. 2016;8(1):65.

4. Jing $X$, et al. Related factors of quality of life of type 2 diabetes patients: a systematic review and meta-analysis. Health Qual Life Outcomes. 2018;16(1):189.

5. Gomes MB, et al. Nationwide multicenter study on the prevalence of overweight and obesity in type 2 diabetes mellitus in the Brazilian population. Arq Bras Endocrinol Metabol. 2006;50(1):136-44.

6. Tobias DK, et al. Body-mass index and mortality among adults with incident type 2 diabetes. N Engl J Med. 2014;370(3):233-44.

7. Magkos F, Hjorth MF, Astrup A. Diet and exercise in the prevention and treatment of type 2 diabetes mellitus. Nat Rev Endocrinol. 2020;16(10):545-55. 
8. Lean ME, et al. Primary care-led weight management for remission of type 2 diabetes (DiRECT): an open-label, cluster-randomised trial. Lancet. 2018;391(10120):541-51.

9. Majumdar SK, Inzucchi SE. Investigational anti-hyperglycemic agents: the future of type 2 diabetes therapy? Endocrine. 2013;44(1):47-58.

10. Bonora E. Antidiabetic medications in overweight/obese patients with type 2 diabetes: drawbacks of current drugs and potential advantages of incretin-based treatment on body weight. Int J Clin Pract Suppl. 2007:154:19-28.

11. Einarson TR, et al. Prevalence of cardiovascular disease in type 2 diabetes: a systematic literature review of scientific evidence from across the world in 2007-2017. Cardiovasc Diabetol. 2018;17(1):83.

12. Vencio S, et al. CAPTURE: a cross-sectional study of the contemporary (2019) prevalence of cardiovascular disease in adults with type 2 diabetes in Brazil. Congr Bras Endocrinol Metabol. 2019. https://doi.org/10.21203/ rs.3.rs-768461/v1.

13. Stratton IM, et al. Association of glycaemia with macrovascular and microvascular complications of type 2 diabetes (UKPDS 35): prospective observational study. BMJ. 2000;321(7258):405-12.

14. Edelman SV, Polonsky WH. Type 2 diabetes in the real world: the elusive nature of glycemic control. Diabetes Care. 2017;40(11):1425-32.

15. Khunti K, et al. Glycaemic control in patients with type 2 diabetes initiating second-line therapy: results from the global DISCOVER study programme. Diabetes Obes Metab. 2020;22(1):66-78.

16. Fellner C. Novel treatments target type-2 diabetes. P T. 2016;41(10):650-3.

17. Vlieghe $P$, et al. Synthetic therapeutic peptides: science and market. Drug Discov Today. 2010;15(1-2):40-56.

18. Recio $C$, et al. The potential therapeutic application of peptides and peptidomimetics in cardiovascular disease. Front Pharmacol. 2016;7:526

19. Drucker DJ. Advances in oral peptide therapeutics. Nat Rev Drug Discov. 2020;19(4):277-89.

20. Aguirre TA, et al. Current status of selected oral peptide technologies in advanced preclinical development and in clinical trials. Adv Drug Deliv Rev. 2016;106(Pt B):223-41.

21. Wong CY, Al-Salami H, Dass CR. Microparticles, microcapsules and microspheres: a review of recent developments and prospects for oral delivery of insulin. Int J Pharm. 2018;537(1-2):223-44.

22. Reed J, Bain S, Kanamarlapudi V. Recent advances in understanding the role of glucagon-like peptide 1. F1000Res. 2020. https://doi.org/10. 12688/f1000research.20602.1.

23. Vrang N, Larsen PJ. Preproglucagon derived peptides GLP-1, GLP-2 and oxyntomodulin in the CNS: role of peripherally secreted and centrally produced peptides. Prog Neurobiol. 2010;92(3):442-62.

24. Turton $\mathrm{MD}$, et al. A role for glucagon-like peptide-1 in the central regulation of feeding. Nature. 1996;379(6560):69-72.

25. Tang-Christensen M, et al. Central administration of GLP-1-(7-36) amide inhibits food and water intake in rats. Am J Physiol. 1996;271(4 Pt 2):R848-56.

26. Flint A, et al. Glucagon-like peptide 1 promotes satiety and suppresses energy intake in humans. J Clin Invest. 1998;101(3):515-20.

27. Verdich C, et al. A meta-analysis of the effect of glucagon-like peptide-1 (7-36) amide on ad libitum energy intake in humans. J Clin Endocrinol Metab. 2001;86(9):4382-9.

28. Williams DL, Baskin DG, Schwartz MW. Evidence that intestinal glucagonlike peptide-1 plays a physiological role in satiety. Endocrinology. 2009;150(4):1680-7.

29. Barrera JG, et al. Hyperphagia and increased fat accumulation in two models of chronic CNS glucagon-like peptide-1 loss of function. J Neurosci. 2011;31(10):3904-13.

30. U.S. Food and Drug Administration (FDA). Ozempic prescribing information. 2017. https://www.accessdata.fda.gov/drugsatfda_docs/label/2017/ 209637lbl.pdf. Accessed 15 Jan 2021.

31. Aroda VR, et al. Comparative efficacy, safety, and cardiovascular outcomes with once-weekly subcutaneous semaglutide in the treatment of type 2 diabetes: Insights from the SUSTAIN 1-7 trials. Diabetes Metab. 2019:45(5):409-18.

32. Kalra S, Sahay R. A review on semaglutide: an oral glucagon-like peptide 1 receptor agonist in management of type 2 diabetes mellitus. Diabetes Ther. 2020;11(9):1965-82.

33. U.S. Food and Drug Administration (FDA). FDA approves first oral GLP-1 treatment for type 2 diabetes. 2019. https://www.fda.gov/news-events/ press-announcements/fda-approves-first-oral-glp-1-treatment-type-2diabetes. Accessed 1 Jan 2021.

34. Agência Nacional de Vigilância Sanitária (ANVISA). Rybelsus (Semaglutida): novo registro. 2020. https://www.gov.br/anvisa/pt-br/assuntos/ medicamentos/novos-medicamentos-e-indicacoes/rybelsus-semag lutida-novo-registro. Accessed 1 Jan 2021.

35. Baekdal TA, et al. A randomized study investigating the effect of omeprazole on the pharmacokinetics of oral semaglutide. Expert Opin Drug Metab Toxicol. 2018;14(8):869-77.

36. Baekdal TA, et al. Effect of oral semaglutide on the pharmacokinetics of lisinopril, warfarin, digoxin, and metformin in healthy subjects. Clin Pharmacokinet. 2019;58(9):1193-203.

37. Kapitza C, et al. Semaglutide, a once-weekly human GLP-1 analog, does not reduce the bioavailability of the combined oral contraceptive, ethinylestradiol/levonorgestrel. J Clin Pharmacol. 2015;55(5):497-504.

38. Davies $\mathrm{M}$, et al. Effect of oral semaglutide compared with placebo and subcutaneous semaglutide on glycemic control in patients with type 2 diabetes: a randomized clinical trial. JAMA. 2017:318(15):1460-70.

39. Aroda VR, et al. PIONEER 1: randomized clinical trial of the efficacy and safety of oral semaglutide monotherapy in comparison with placebo in patients with type 2 diabetes. Diabetes Care. 2019;42(9):1724-32.

40. Rodbard HW, et al. Oral semaglutide versus empagliflozin in patients with type 2 diabetes uncontrolled on metformin: the PIONEER 2 trial. Diabetes Care. 2019;42(12):2272-81.

41. Rosenstock J, et al. Effect of additional oral semaglutide vs sitagliptin on glycated hemoglobin in adults with type 2 diabetes uncontrolled with metformin alone or with sulfonylurea: the PIONEER 3 randomized clinical trial. JAMA. 2019;321(15):1466-80.

42. Pratley $\mathrm{R}$, et al. Oral semaglutide versus subcutaneous liraglutide and placebo in type 2 diabetes (PIONEER 4): a randomised, double-blind, phase 3a trial. Lancet. 2019:394(10192):39-50.

43. Mosenzon $\mathrm{O}$, et al. Efficacy and safety of oral semaglutide in patients with type 2 diabetes and moderate renal impairment (PIONEER 5): a placebocontrolled, randomised, phase 3a trial. Lancet Diabetes Endocrinol. 2019:7(7):515-27.

44. Husain M, et al. Oral semaglutide and cardiovascular outcomes in patients with type 2 diabetes. N Engl J Med. 2019;381(9):841-51.

45. Pieber TR, et al. Efficacy and safety of oral semaglutide with flexible dose adjustment versus sitagliptin in type 2 diabetes (PIONEER 7): a multicentre, open-label, randomised, phase 3a trial. Lancet Diabetes Endocrinol. 2019;7(7):528-39

46. Zinman B, et al. Efficacy, safety, and tolerability of oral semaglutide versus placebo added to insulin with or without metformin in patients with type 2 diabetes: the PIONEER 8 trial. Diabetes Care. 2019;42(12):2262-71.

47. Leighton $E$, Sainsbury CA, Jones GC. A practical review of C-peptide testing in diabetes. Diabetes Ther. 2017;8(3):475-87.

48. Blundell J, et al. Oral semaglutide reduces appetite and energy intake and improves control of eating in subjects with type 2 diabetes (Abstract \#753). Barcelona: 55th Annual Meeting of the European Association for the Study of Diabetes (EASD); 2019.

49. Rodbard HW, Dougherty T, Taddei-Allen P. Efficacy of oral semaglutide: overview of the PIONEER clinical trial program and implications for managed care. Am J Manag Care. 2020;26(16 Suppl):S335-43.

50. Chubb B, et al. Once-daily oral semaglutide versus injectable GLP-1 RAs in people with type 2 diabetes inadequately controlled on basal insulin: systematic review and network meta-analysis. Diabetes Ther. 2021;12(5):1325-39.

51. Del Olmo-Garcia MI, Merino-Torres JF. GLP-1 receptor agonists and cardiovascular disease in patients with type 2 diabetes. J Diabetes Res. 2018:2018:4020492.

52. Marso SP, et al. Semaglutide and cardiovascular outcomes in patients with type 2 diabetes. N Engl J Med. 2016;375(19):1834-44.

53. Ioannidis I. Diabetes treatment in patients with renal disease: is the landscape clear enough? World J Diabetes. 2014;5(5):651-8.

54. Davies M, Chatterjee S, Khunti K. The treatment of type 2 diabetes in the presence of renal impairment: what we should know about newer therapies. Clin Pharmacol. 2016;8:61-81.

55. Kristensen SL, et al. Cardiovascular, mortality, and kidney outcomes with GLP-1 receptor agonists in patients with type 2 diabetes: a systematic review and meta-analysis of cardiovascular outcome trials. Lancet Diabetes Endocrinol. 2019:7(10):776-85. 
56. Mann JFE, et al. Liraglutide and renal outcomes in type 2 diabetes. N Engl J Med. 2017;377(9):839-48.

57. Pasternak B, et al. Use of glucagon-like peptide 1 receptor agonists and risk of serious renal events: Scandinavian Cohort Study. Diabetes Care. 2020;43(6):1326-35.

58. ClinicalTrials.gov. A research study to see how semaglutide works compared to placebo in people with type 2 diabetes and chronic kidney disease (FLOW); NCT03819153. 2019. https://clinicaltrials.gov/ct2/show/ NCT03819153. Accessed 5 Aug 2021

59. Yamada Y, et al. Dose-response, efficacy, and safety of oral semaglutide monotherapy in Japanese patients with type 2 diabetes (PIONEER 9): a 52-week, phase 2/3a, randomised, controlled trial. Lancet Diabetes Endocrinol. 2020;8(5):377-91.

60. Yabe D, et al. Safety and efficacy of oral semaglutide versus dulaglutide in Japanese patients with type 2 diabetes (PIONEER 10): an open-label, randomised, active-controlled, phase 3a trial. Lancet Diabetes Endocrinol. 2020;8(5):392-406.

61. Frias JP. Safety of once-weekly glucagon-like peptide-1 receptor agonists in patients with type 2 diabetes. J Fam Pract. 2018;67(6 suppl):S25-34.

62. Baxter $M$, et al. Estimating the impact of better management of glycaemic control in adults with Type 1 and Type 2 diabetes on the number of clinical complications and the associated financial benefit. Diabet Med. 2016;33(11):1575-81.
63. Malkin SJP, et al. The long-term cost-effectiveness of oral semaglutide in the Netherlands based on the PIONEER 2, 3 and 4 randomized controlled trials. Diabetes Res Clin Pract. 2021;175:108759.

64. Bain SC, et al. Oral semaglutide versus empagliflozin, sitagliptin and liraglutide in the UK: long-term cost-effectiveness analyses based on the PIONEER clinical trial programme. Diabetes Ther. 2020;11(1):259-77.

65. DeFronzo RA. Current issues in the treatment of type 2 diabetes. Overview of newer agents: where treatment is going. Am J Med. 2010;123(3 Suppl):S38-48.

66. Defronzo RA. Banting lecture. From the triumvirate to the ominous octet: a new paradigm for the treatment of type 2 diabetes mellitus. Diabetes. 2009;58(4):773-95.

67. Muller TD, et al. Glucagon-like peptide 1 (GLP-1). Mol Metab. 2019:30:72-130.

68. Mamontova ED, et al. Direct effect of the synthetic analogue of glucagon-like peptide type 1, liraglutide, on mature adipocytes is realized through adenylate-cyclase-dependent enhancing of insulin sensitivity. Biochemistry. 2021;86(3):350-60.

\section{Publisher's Note}

Springer Nature remains neutral with regard to jurisdictional claims in published maps and institutional affiliations.
Ready to submit your research? Choose BMC and benefit from:

- fast, convenient online submission

- thorough peer review by experienced researchers in your field

- rapid publication on acceptance

- support for research data, including large and complex data types

- gold Open Access which fosters wider collaboration and increased citations

- maximum visibility for your research: over $100 \mathrm{M}$ website views per year

At BMC, research is always in progress.

Learn more biomedcentral.com/submissions 